\title{
Nervous Debility
}

National Cancer Institute

\section{Source}

National Cancer Institute. Nervous Debility. NCI Thesaurus. Code C34846.

An episode of acute, severe anxiety or depression associated with an inability to function as normal. 